\title{
A Clinicoradiological Assessment following Surgical Intervention in Patients of Cervical Spondylotic Myelopathy: An Institutional Experience
}

\author{
Maneet Gill ${ }^{1}$ Vikas Maheshwari ${ }^{2, \odot ~} \quad$ Arun Kumar Yadav $^{3} \quad$ Rushikesh Gadhavi ${ }^{4}$ \\ ${ }^{1}$ Department of Neurosurgery, Army Hospital (R\&R), New Delhi, \\ India \\ 2Department of Neurosurgery, Command Hospital, Bangalore, India \\ Address for correspondence Vikas Maheshwari, MCh, \\ ${ }^{3}$ Department of PSM, Armed Forces Medical College, Pune, India \\ Department of Neurosurgery, Command Hospital, Bangalore, India \\ (e-mail: drvikas08@rediffmail.com). \\ ${ }^{4}$ Department of Neurosurgery, Armed Forces Medical College, \\ Pune, India \\ Indian J Neurosurg 2022;11:241-247
}

Abstract

Keywords

- cervical spondylosis

- myelopathy

- laminoplasty
Introduction To critically analyze the functional and radiological improvement in patients of cervical spondylotic myelopathy (CSM) who underwent surgical decompression by an anterior or posterior approach.

Materials and Methods A retrospective study was conducted in a tertiary-level Armed Forces Hospital from June 2015 to December 2019. Preoperative assessment included a thorough clinical examination and functional and radiological assessment. The surgical decompression was done by an anterior or a posterior approach with instrumented fusion. Anterior approach was taken for single or two-level involvement and posterior approach for three or more cervical levels. The pre and postoperative neurological outcome was assessed by Nurick and modified Japanese Orthopaedic Association (mJOA) score along with measurement of canal diameter and cross-sectional area.

Results A total of 120 patients of CSM who underwent surgical decompression were analyzed. Both the groups were comparable and had male predominance. A total of 59 patients underwent surgical decompression by an anterior approach and the remaining 61 patients by the posterior approach. Out of the 59 patients operated by the anterior approach, 30 (50.85\%) underwent anterior cervical discectomy and fusion (ACDF); remaining 29 (49.15\%) underwent anterior cervical corpectomy and fusion (ACCF). In the posterior group ( $n=61), 26(42.6 \%)$ patients underwent laminoplasty and the remaining $35(57.4 \%)$ underwent laminectomy with or without instrument fusion. Sixteen patients out of these underwent lateral mass fixation and the remaining 19 underwent laminectomy. There was functional improvement (mJOA and Nurick grade) and radiological improvement in both subgroups, which were statistically significant $(p<0.0001)$.

Conclusion A prompt surgical intervention in moderate-to-severe cases of CSM either by the anterior or the posterior approach is essential for good outcome.
DOI https://doi.org/ 10.1055/s-0041-1726607 ISSN 2277-954X (c)2022. Neurological Surgeons' Society of India.

This is an open access article published by Thieme under the terms of the Creative Commons Attribution-NonDerivative-NonCommercial-License, permitting copying and reproduction so long as the original work is given appropriate credit. Contents may not be used for commercial purposes, or adapted, remixed, transformed or built upon. (https://creativecommons.org/licenses/by-nc-nd/4.0/).

Thieme Medical and Scientific Publishers Pvt. Ltd. A-12, 2nd Floor, Sector 2, Noida-201301 UP, India 


\section{Introduction}

Cervical spondylosis is the most common nontraumatic cause of myelopathy in the cervical spine. ${ }^{1}$ The diagnosis of cervical spondylotic myelopathy (CSM) can be difficult due to its insidious onset, tendency to remaining stationary or at times marred by episodic worsening. It commonly presents as spasticity of lower limbs with gait difficulty followed by numbness in upper limbs or loss of dexterity. ${ }^{2}$

CSM was first defined by Brain et al in 1952. ${ }^{3}$ The process leading to pathological changes resulting in cervical spondylosis and subsequently CSM are multifactorial. The natural history of CSM was further dwelt upon by Lees and Turner in $1963^{4}$ and by Nurick in $1972 . .^{5}$ The process gets initiated with degeneration of cervical disc, leading to decreased disc space. There is increased mechanical pressure on the end plates of the vertebral bodies, resulting in formation of osteophytes. Additionally, presence of ossified posterior longitudinal ligament (OPLL), as seen commonly in Asian population, further contributes towards CSM. ${ }^{6,7}$ Dorsally, there may be ligament or facet joint hypertrophy. These degenerative processes result in static compression and any sudden flexion or extension movement of cervical spine can exacerbate the cord compression. These static factors may have a significant impact in patients of congenital stenosis of spinal canal. ${ }^{8}$ Apart from these static and dynamic compression, another theory postulated is that of spinal cord ischemia from compression of vascular channels and venous congestion. ${ }^{9}$

The most common cervical levels ( $\mathrm{C} 5-\mathrm{C} 7$ ) affected in CSM correspond to the most vulnerable vascular supply. However, experimental validation of cord ischemia in CSM is yet to be ratified. ${ }^{10,11}$

The exact prevalence of CSM is unclear due to its relentless and progressive course. It is currently limited to population bases studies. In USA, number of CSM patients admitted has increased two-fold from 1993 to 2002 (3.73 to 7.88 per 100000)..$^{12}$ This incidence is likely to increase further, with the increase in elderly population. Wu et $\mathrm{al}^{13}$ from Taiwan estimated that CSM related hospitalization was 4.04 per 100000 person years. They also observed that older age and men had a higher incidence of CSM. Nouri et al ${ }^{14}$ estimated that incidence and prevalence of CSM-related spinal cord injury (SCI) in North America is 4.10 and 6.05 per 100000 , respectively.

Morphologically, Taitz et al ${ }^{15}$ after analyzing 214 cadaveric skeletons reported that Whites had a larger canal diameter and transverse diameter of the cervical canal than Blacks. However, Lee $\mathrm{MJ}^{16}$ did not find any significant difference between the two population groups and suggested that clinical presentation must be taken into account and not just these ratios. Singh et $\mathrm{al}^{17}$ from India in their hospital-based case control study of 200 cases have also concluded that assessment of various morphological parameters by CT/MRI is unnecessary and results in cost escalation.

The present study was undertaken to critically assess the neurological and radiological outcome and establish its statistical validity.

\section{Materials and Methods}

A retrospective hospital-based observational study was conducted in a tertiary-level Armed Forces Hospital from June 2015 to December 2019. The study was approved by the ethical committee of our institute (MRU 2248).

\section{Inclusion Criteria}

- Patients of CSM or myeloradiculopathy.

- Patients of OPLL.

- Bowel and bladder involvement.

- Failure of conservative management.

- Worsening quality of life.

\section{Exclusion Criteria}

- Neoplastic conditions.

- Posttraumatic cases.

- Systemic disorders such as rheumatoid arthritis.

- Metabolic disorders.

- Previous history of surgery.

Preoperative assessment included a thorough clinical examination, and functional assessment was done by using Nurick grade and modified Japanese Orthopaedic Association (mJOA) score (-Tables 1 and 2 ). Radiological assessment was done through digital X-ray, CT, and MRI of cervical spine. A glass marking pencil was used to mark well-defined points on the $\mathrm{X}$ ray. RadiAnt software for CT scan and Canvas Workstation Software for MRI was used to assess sagittal canal diameter (CD) and cross-sectional area (CSA). This data was recorded and analyzed using Microsoft Excel spreadsheet. These parameters were assessed postoperatively with patient's improvement in functional status, increase in CSA, and CD. The patients were assessed postoperatively at 48 hours, 1 , 3 and 6 months and annually thereafter. The CT scan was done within a fortnight; MRI when clinically indicated or usually by 3 to 4 months. Neck was immobilized with hard cervical collar for 3 to 6 months.

Anterior and posterior approaches were decided based on number of cervical levels involved, patient's age and general condition, comorbidities, and radiological findings. In general, the posterior approach was taken for $\geq 3$ levels and anterior approach for single and two level (s); seldom, it was at the discretion of senior most surgeon.

Atotal of 120 patients ofCSMwhounderwentsurgicaldecompression were analyzed. There were 100 males and 20 females.

Table 1 Nurick grade

\begin{tabular}{|l|l|}
\hline 0 & $\begin{array}{l}\text { Signs or symptoms of root involvement but without } \\
\text { evidence of spinal cord disease }\end{array}$ \\
\hline 1 & Signs of spinal cord disease but no difficulty in walking \\
\hline 2 & $\begin{array}{l}\text { Slight difficulty in walking which did not prevent full-time } \\
\text { employment }\end{array}$ \\
\hline 3 & $\begin{array}{l}\text { Difficulty in walking which prevented full-time employment } \\
\text { or the ability to do all housework, but which was not so } \\
\text { severe as to require someone else's help to walk }\end{array}$ \\
\hline 4 & $\begin{array}{l}\text { Able to walk only with someone else's help or with the aid } \\
\text { of a frame }\end{array}$ \\
\hline 5 & Chair bound or bedridden \\
\hline
\end{tabular}


Table 2 Modified Japanese orthopaedic scoring system

\begin{tabular}{|l|l|}
\hline \multicolumn{2}{|l|}{ Motor dysfunction } \\
\hline Upper extremities \\
\hline 0 & Unable to move hands \\
\hline 1 & Unable to eat with a spoon but able to move hands \\
\hline 2 & Unable to button shirt but able to eat with a spoon \\
\hline 3 & Able to button shirt with great difficulty \\
\hline 4 & Able to button shirt with slight difficulty \\
\hline Lower extremities \\
\hline 0 & Complete loss of motor and sensory function \\
\hline 1 & Sensory preservation without ability to move legs \\
\hline 2 & Able to move legs but unable to walk \\
\hline 3 & Able to walk on flat floor with a walking aid (cane or crutch) \\
\hline 4 & Able to walk up and/or downstairs w/aid of a handrail \\
\hline 5 & Moderate-to-significant lack of stability but able to walk \\
\hline 6 & up and/or downstairs without handrail \\
\hline 7 & \begin{tabular}{l} 
reciprocation lack of stability but able to walk unaided with smooth \\
\hline Sensory dysfunction
\end{tabular} \\
\hline Upper extremities \\
\hline 0 & Complete loss of hand sensation \\
\hline 1 & Severe sensory loss or pain \\
\hline 2 & Mild sensory loss \\
\hline 3 & No sensory loss \\
\hline Sphincter dysfunction \\
\hline 0 & Unable to micturate voluntarily \\
\hline 1 & Marked difficulty in micturition \\
\hline 2 & Mild-to-moderate difficulty in micturition \\
\hline 3 & Normal micturition \\
\hline
\end{tabular}

The mean age of patient was 52.9 years (range $30-74$ years). Preoperative characteristics of subgroups in anterior and posterior approach are given in - Table 3 and - Table 4 , respectively. Both the subgroups within the anterior and posterior approach were comparable and had a male predominance. Follow-up averaged 38.4 months (range 4-54 months). In the posterior approach, an average of 4.4 levels (range 3-6 levels) were involved in the laminoplasty group and 4.2 levels (range 3-5 levels) in the laminectomy group. Patients who underwent single- or two-level anterior cervical discectomy and fusion (ACDF) had titanium/PEEK spacer insertion, while those with anterior cervical discectomy and fusion (ACCF) had expandable cage or Paramesh along with plating and screw fixation. In the posterior approach, laminoplasty was done by the standard Hirabayashi's technique, and fixation was done by laminoplasty plates and screws.

\section{Statistical Analysis}

Quantitative variables were described using mean and standard deviation (SD), while qualitative variables were described using numbers and percentages. " $t$ " test was used to find out the difference between subgroups for quantitative variable. Chi-square test was used for comparing qualitative variables in the group. Repeated measure analysis was used for repeated values over a period of time. $p$ value of < 0.05 was taken as significant. Statistical analysis was done using STATA 13 Version I/C.

\section{Results}

A total of 59 patients underwent surgical decompression by an anterior approach, and the remaining 61 patients had a

Table 3 Preop comparison of anterior approach

\begin{tabular}{|l|l|l|l|}
\hline & ACDF $(\boldsymbol{n}=\mathbf{3 0})$ & ACCF $(\boldsymbol{n}=\mathbf{2 9})$ & $p$-Value \\
\hline Age (years) & $47.7(9.4)$ & $53.9(7.9)$ & 0.08 \\
\hline $\begin{array}{l}\text { Sex } \\
\quad \text { Males }\end{array}$ & $26(86.7 \%)$ & $24(82.7 \%)$ & $0.6^{a}$ \\
\hline Females & $4(13.3 \%)$ & $5(17.24 \%)$ & \\
\hline CSA $\left(\mathrm{mm}^{3}\right)$ & $1.4(0.4)$ & $1.7(0.4)$ & 0.04 \\
\hline CD $(\mathrm{mm})$ & $10.9(3.1)$ & $11(1.2)$ & 0.9 \\
\hline
\end{tabular}

Abbreviations: ACCF, anterior cervical corpectomy and fusion; ACDF, anterior cervical discectomy and fusion; CSA, cross-sectional area; CD, canal diameter.

${ }^{a}$ Chi-square test.

Table 4 Preop comparison of posterior approach $(n=61)$

\begin{tabular}{|l|l|l|l|}
\hline & Laminoplasty $(\boldsymbol{n}=\mathbf{2 6})$ & Laminectomy $(\boldsymbol{n}=\mathbf{3 5})$ & $\boldsymbol{p}$-Value \\
\hline Age (years) & $52.8(7.9)$ & $56.9(8.6)$ & 0.06 \\
\hline Sex & & & \\
\hline Males & $21(80.8 \%)$ & $29(82.9 \%)$ & $0.9^{a}$ \\
Females & $5(19.2 \%)$ & $6(17.1 \%)$ & \\
\hline CSA $\left(\mathrm{mm}^{3}\right)$ & $1.09(0.4)$ & $1.2(0.3)$ & 0.4 \\
\hline CD $(\mathrm{mm})$ & $8.96(1.4)$ & $9.9(1.4)$ & 0.01 \\
\hline
\end{tabular}

Abbreviations: CSA, cross-sectional area; $\mathrm{CD}$, canal diameter.

${ }^{a}$ Chi-square test. 
posterior approach. Out of the 59 patients operated by the anterior approach, 30 (50.85\%) underwent ACDF and the remaining $29(49.15 \%)$ underwent ACCF. In the posterior group ( $n=61), 26$ (42.6\%) patients underwent laminoplasty and the remaining $35(57.4 \%)$ underwent laminectomy. Sixteen patients out of these underwent lateral mass fixation and the remaining 19 underwent laminectomy alone.

Patients who underwent ACDF showed functional improvement in Nurick grade (2.2 to 1.3 ) and mJOA score (11.1 to 14.9) at the end of 1 year, which was statistically significant $(p<0.0001)$. Similarly, in patients who underwent ACCF, there was functional improvement in Nurick grade (2.9 to 1.4) and mJOA score (8.7 to 14.5) at the end of 1 year which was statistically significant $(p<0.0001)$.

Patients who underwent laminoplasty showed functional improvement in Nurick grade (3.3 to 1.8) and mJOA score (7.1 to
13.2) at the end of 1 year which was statistically significant ( $p$ $<0.0001$ ). Similarly, in patients who underwent laminectomy \pm fusion, there was functional improvement in Nurick grade (3.3 to 1.9 ) and mJOA score ( 8.5 to 13.6 ) at the end of 1 year, which was statistically significant $(p<0.0001)$ ( - Table 5).

There was increase in CD and CSA in patients of both anterior and posterior subgroups which was statistically significant ( Tables 6 and 7 ).

The clinical improvement as assessed by mJOA and Nurick grade showed a better neurological recovery in patients of ACDF than ACCF in the initial months, but the two tend to merge by 12 months (-Figs. 1 and $\mathbf{2}$ ). Similarly, in the posterior group, clinical improvement (mJOA and Nurick) showed an initial better response in laminoplasty than in laminectomy patients but there was no significant difference at 12 months (-Figs. 3 and 4).

Table 5 Functional improvement

\begin{tabular}{|c|c|c|c|c|c|c|c|}
\hline Approach & Scale & Group & Preop & At $1 \mathrm{mo}$ & At 6 mo & At $12 \mathrm{mo}$ & $p$-Value \\
\hline \multirow[t]{2}{*}{ Anterior } & \multirow[t]{2}{*}{ Nurick } & $\begin{array}{l}\text { ACDF } \\
(n=30)\end{array}$ & $2.2(1)$ & $1.5(0.8)$ & $1.4(0.7)$ & $1.3(0.6)$ & \multirow[t]{2}{*}{$<0.0001$} \\
\hline & & $\begin{array}{l}\text { ACCF } \\
(n=29)\end{array}$ & $2.9(0.9)$ & $2.3(0.8)$ & $1.9(0.8)$ & $1.4(0.7)$ & \\
\hline \multirow[t]{2}{*}{ Posterior } & \multirow[t]{2}{*}{ Nurick } & $\begin{array}{l}\text { Laminoplasty } \\
(n=26)\end{array}$ & $3.3(0.9)$ & $2.5(0.9)$ & $2.2(0.7)$ & $1.8(0.7)$ & \multirow[t]{2}{*}{$<0.0001$} \\
\hline & & $\begin{array}{l}\text { Laminectomy } \\
(n=35)\end{array}$ & $3.3(1.1)$ & $2.7(1.3)$ & $2.4(1.4)$ & $1.9(1.1)$ & \\
\hline \multirow[t]{2}{*}{ Anterior } & \multirow[t]{2}{*}{$\mathrm{mJOA}$} & $\begin{array}{l}\text { ACDF } \\
(n=30)\end{array}$ & $11.1(2.8)$ & $14.3(1.5)$ & $14.5(1.4)$ & $14.9(1.1)$ & \multirow[t]{2}{*}{$<0.0001$} \\
\hline & & $\begin{array}{l}\text { ACCF } \\
(n=29)\end{array}$ & $8.7(2)$ & $13.1(1.6)$ & $13.4(1.5)$ & $14.5(1.2)$ & \\
\hline \multirow[t]{2}{*}{ Posterior } & \multirow[t]{2}{*}{$\mathrm{mJOA}$} & $\begin{array}{l}\text { Laminoplasty } \\
(n=26)\end{array}$ & $7.1(2.5)$ & $11.8(2)$ & $12.6(1.8)$ & $13.2(1.8)$ & \multirow[t]{2}{*}{$<0.0001$} \\
\hline & & $\begin{array}{l}\text { Laminectomy } \\
(n=35)\end{array}$ & $8.5(2.7)$ & $12.5(2.2)$ & $13.1(2.2)$ & 13.6 (1.9) & \\
\hline
\end{tabular}

Abbreviations: ACCF, anterior cervical corpectomy and fusion; ACDF, anterior cervical discectomy and fusion; mJOA, modified Japanese Orthopaedic Association.

Table 6 Radiological improvement in anterior group

\begin{tabular}{|l|l|l|l|l|}
\hline Type of Surgery & Characteristics & Preop & Postop & $p$-Value \\
\hline \multirow{2}{*}{ ACDF $(n=30)$} & CD & $10.9(3.1)$ & $12.9(2.7)$ & $<0.0001$ \\
\cline { 2 - 5 } & CSA & $1.4(0.4)$ & $1.8(0.4)$ & $<0.0001$ \\
\hline \multirow{2}{*}{ ACCF $(n=29)$} & CD & $11.0(1.24)$ & $12.5(1.3)$ & $<0.0001$ \\
\cline { 2 - 5 } & CSA & $1.7(0.4)$ & $2.19(0.4)$ & $<0.0001$ \\
\hline
\end{tabular}

Abbreviations: ACCF, anterior cervical corpectomy and fusion; ACDF, anterior cervical discectomy and fusion; CSA, cross-sectional area; CD, canal diameter.

Table 7 Radiological improvement in posterior group

\begin{tabular}{|l|l|l|l|l|}
\hline Type of surgery & Characteristics & Preop & Postop & $p$-Value \\
\hline \multirow{2}{*}{ Laminoplasty $(n=26)$} & CD & $8.9(1.4)$ & $12.2(0.98)$ & $<0.0001$ \\
\cline { 2 - 5 } & CSA & $1.1(0.4)$ & $1.6(0.5)$ & $<0.0001$ \\
\hline \multirow{2}{*}{ Laminectomy $(n=35)$} & CD & $9.9(1.4)$ & $11.3(1.3)$ & $<0.0001$ \\
\cline { 2 - 5 } & CSA & $1.16(0.3)$ & $1.6(0.3)$ & $<0.0001$ \\
\hline
\end{tabular}

Abbreviations: CSA, cross-sectional area; $C D$, canal diameter. 


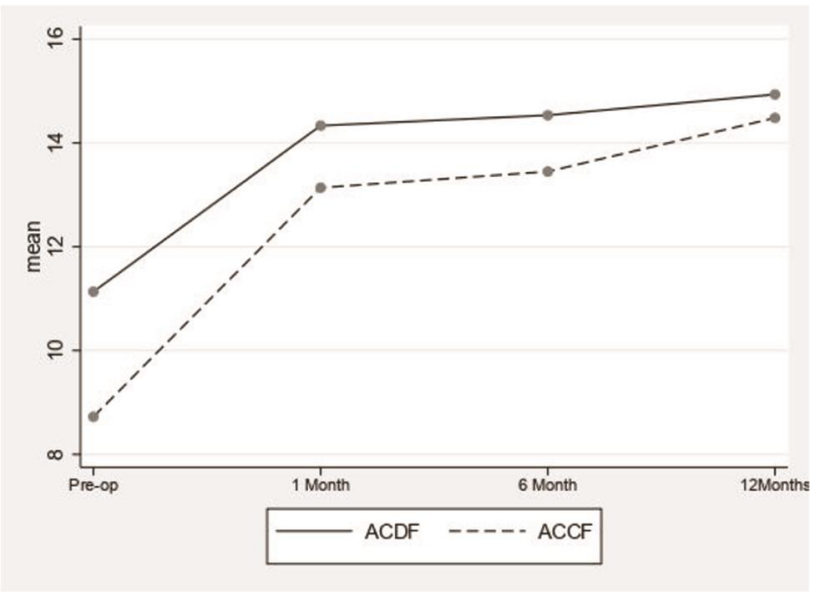

Fig. 1 Clinical profile with modified Japanese Orthopaedic Association (mJOA) score in anterior approach.

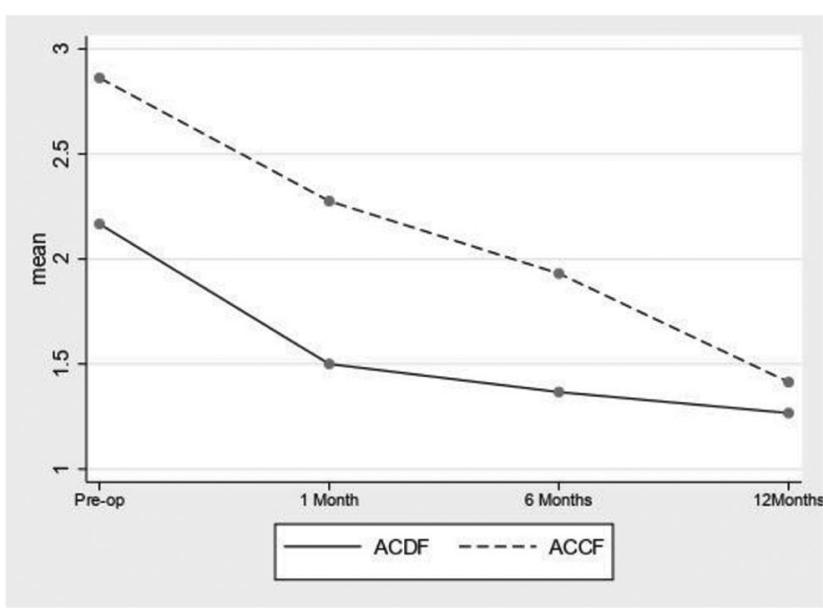

Fig. 2 Clinical profile with Nurick grade in anterior approach.

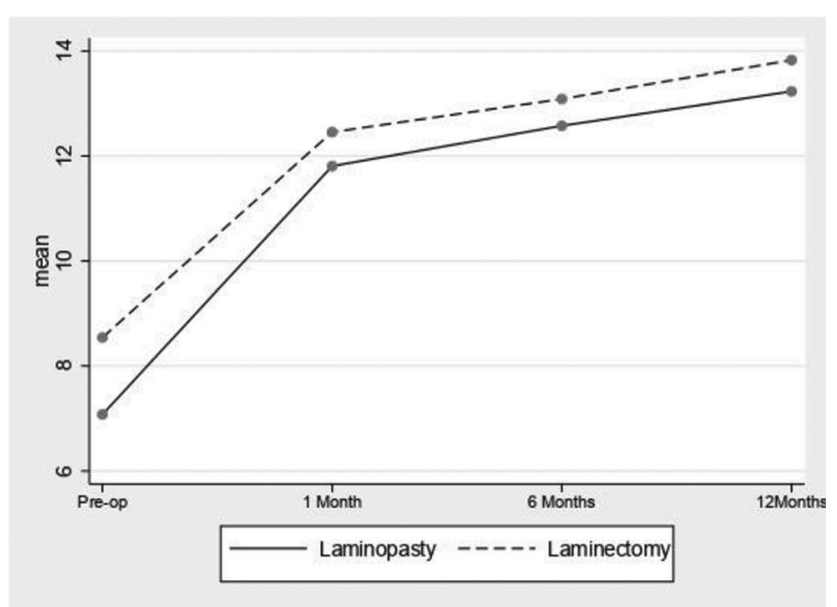

Fig. 3 Clinical profile with modified Japanese Orthopaedic Association $(\mathrm{mJOA})$ score in posterior approach.

\section{Discussion}

CSM and radiculopathy is a progressive debilitating illness. Law et $\mathrm{al}^{18}$ identified certain poor prognostic factors with

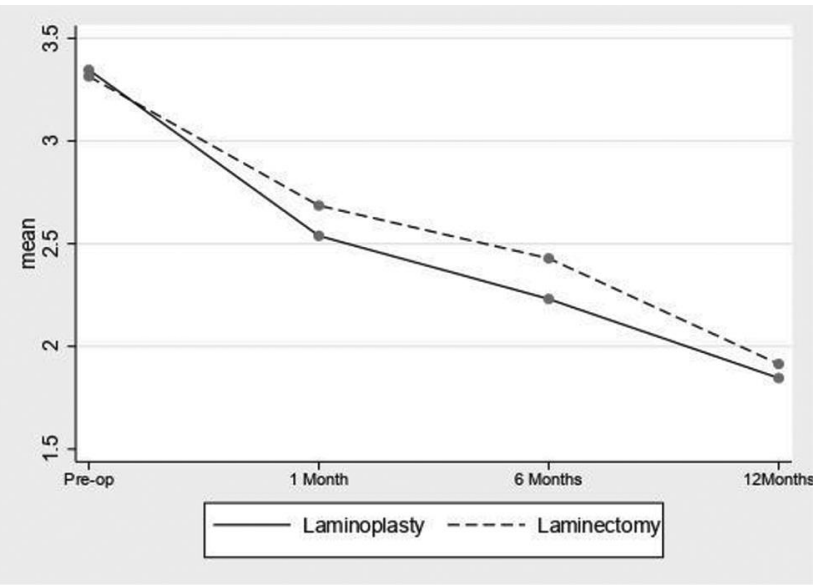

Fig. 4 Clinical profile with Nurick grade in posterior approach.

Table 8 Factors affecting surgical approach

\begin{tabular}{|l|l|l|}
\hline $\begin{array}{l}\text { Sagittal } \\
\text { alignment }\end{array}$ & Kyphosis & $\begin{array}{l}\text { Fixed } \\
\text { Anterior Flexible } \\
\text { >Anterior or posterior } \\
\text { with fusion }\end{array}$ \\
\cline { 2 - 3 } & Neutral or lordotic & $\begin{array}{l}\text { Posterior (laminoplasty) } \\
\text { > Anterior }\end{array}$ \\
\hline $\begin{array}{l}\text { Number of } \\
\text { levels }\end{array}$ & $\geq 3$ & $\begin{array}{l}\text { Posterior (laminoplasty) } \\
\text { > Anterior }\end{array}$ \\
\hline \multirow{2}{*}{$\begin{array}{l}\text { Age and } \\
\text { comorbidities }\end{array}$} & $\begin{array}{l}\text { Elderly, greater } \\
\text { comorbidities }\end{array}$ & Anterior > posterior \\
\cline { 2 - 3 } & Healthier & Posterior > anterior \\
\hline \multirow{2}{*}{$\begin{array}{l}\text { Preoperative } \\
\text { pain levels }\end{array}$} & Moderate-high & $\begin{array}{l}\text { Anterior or posterior } \\
\text { with fusion }\end{array}$ \\
\cline { 2 - 3 } & None-low & $\begin{array}{l}\text { Posterior (laminoplasty) } \\
\text { or anterior }\end{array}$ \\
\hline \multirow{2}{*}{ Instability } & Yes & $\begin{array}{l}\text { Anterior or posterior } \\
\text { with fusion }\end{array}$ \\
\cline { 2 - 3 } & No & $\begin{array}{l}\text { Posterior (laminoplasty) } \\
\text { or anterior }\end{array}$ \\
\hline
\end{tabular}

conservative treatment, which included progression of symptoms, presence of myelopathy $>6$ months duration, and transverse area of cord $<40 \mathrm{~mm}$. Surgical decompression of the affected spinal segments is required to arrest the further progression of the disease. ${ }^{19}$ The optimal surgical approach has been under investigation for the last three decades and hence surgical decision-making is difficult at times. The other factors taken into consideration before surgery being preop function and pain, patient's age and health, sagittal involvement, and other radiological features ( - Table 8 ). The broad consensus is that an anterior approach is preferred when only 1 or 2 levels are involved. However, when 3 or more levels are involved, posterior approach should be considered. ${ }^{20}$

Anterior procedures, namely, ACDF and ACCF have the following advantages: direct decompression, muscle-sparing dissection, correction of cervical kyphosis, and lower infection rates. 
The literature on arthroplasty for patients with myelopathy is limited. Hu et a $^{21}$ studied data of eight prospective randomized control trials (RCT) investigating the outcome of ACDF and cervical disc arthroplasty for treatment of 1to 2-level CSM. They concluded that cervical arthroplasty be reserved for patients with acute neurological deficits (herniated disc), and ACDF is better suited for degenerative/myelopathic changes of the cervical spine. Higher quality clinical studies with longer follow-up are needed to confirm the superiority of arthroplasty over ACDF in cases of cervical myelopathy.

The posterior approach procedure (laminoplasty or laminectomy + fusion) allows for a wider decompression. If there is focal kyphosis and the compressive pathology is posterior, then a combined approach should be considered.

The current evidence in literature is not clear as to which particular approach is superior for multilevel ( $\geq 3$ levels) cervical myelopathy cases. Gupta et $\mathrm{al}^{22}$ report a good functional outcome following three level cervical corpectomy with uninstrumented fusion. Luo et $\mathrm{al}^{23}$ after studying 10 high quality comparative studies concluded that there was no apparent difference in neurological recovery at 24 months. These findings were consistent with earlier studies. ${ }^{24,25}$ Our study too shows that though there is marginal improvement initially between the two subgroups, but there is no apparent difference at 12 to 14 months (-Figs. 1 and 2).

Some of the complications of anterior procedures include hoarseness of voice $(3 \%-11 \%)$, dysphagia $(2 \%-48 \%)$, and vertebral artery injury (0.03\%). ${ }^{26}$ In our study, six patients had transient dysphagia which improved slowly over 6 to 9 months. One patient had transient hoarseness of voice. There were no cases of worsening of neurological deficit, dural leak, wound complications, or implant failure.

The common complications of posterior approach are as follows: postoperative axial neck pain, kyphosis, segmental instability, and delayed C5 nerve route injury. ${ }^{27,28}$ Two patients of laminoplasty in our study had worsening of neurological status in the immediate postop period. They were reexplored; the offending "open door" was found to be pressing on the thecal sac and hence was removed. Steroids were administered and tapered over 1 week. Both these patients showed gradual neurological recovery by the end of 3 months. There were three cases of C5 nerve route injury ( 2 in laminectomy + fusion and 1 in laminoplasty). Transient weakness of C5-6 root has also been mentioned by Yoshida ( 3 out of 40 cases) ${ }^{29}$ and O'Brien ${ }^{30}$ ( 1 out of 10 ). In Hirabayashi's series of 90 laminoplasties, 7 patients had transient weakness of C5-6; 4 on the open side and 3 on the hinged side. ${ }^{31}$ Although the exact cause is not known, it is postulated that there is tethering of nerve roots with the dorsal migration of the cord.

The perioperative complications of a combined (anterior and posterior) approach are significantly higher when compared to anterior or posterior approach alone. ${ }^{32}$ This may be because combined approach is reserved for patients with severe kyphosis, complex pathologies, and severe spinal instability, resulting in longer surgical time.

\section{Conclusion}

An early diagnosis and prompt surgical intervention before the spinal cord dysfunction sets in is essential for good outcome. Surgical intervention either by the anterior or the posterior approach aims to decompress the cord, restore cervical lordosis, and prevent further kyphosis by stabilization procedures. Further high-quality RCTs with long-term follow-up are required to assess the etiopathogenesis of CSM and in formulation of an ideal surgical procedure.

\section{Conflict of Interest}

None declared.

\section{References}

1 Baron EM, Young WF. Cervical spondylotic myelopathy: a brief review of its pathophysiology, clinical course, and diagnosis. Neurosurgery 2007;60(1, Suppl 1) :S35-S41

2 Furlan JC, Kalsi-Ryan S, Kailaya-Vasan A, Massicotte EM, Fehlings MG. Functional and clinical outcomes following surgical treatment in patients with cervical spondylotic myelopathy: a prospective study of 81 cases. J Neurosurg Spine 2011;14(3):348-355

3 Brain WR, Northfield D, Wilkinson M. The neurological manifestations of cervical spondylosis. Brain 1952;75(2):187-225

4 Lees F, Turner JW. Natural history and prognosis of cervical spondylosis. BMJ 1963;2(5373) :1607-1610

5 Nurick S. The pathogenesis of the spinal cord disorder associated with cervical spondylosis. Brain 1972;95(1):87-100

6 Kumaresan S, Yoganandan N, Pintar FA, Maiman DJ, Goel VK. Contribution of disc degeneration to osteophyte formation in the cervical spine: a biomechanical investigation. J Orthop Res 2001;19(5):977-984

7 Hoff JT, Wilson CB. The pathophysiology of cervical spondylotic radiculopathy and myelopathy. Clin Neurosurg 1977;24: 474-487

8 Moore AP, Blumhardt LD. A prospective survey of the causes of non-traumatic spastic paraparesis and tetraparesis in 585 patients. Spinal Cord 1997;35(6):361-367

9 Yue WM, Tan SB, Tan MH, Koh DC, Tan CT. The Torg-Pavlov ratio in cervical spondylotic myelopathy: a comparative study between patients with cervical spondylotic myelopathy and a nonspondylotic, nonmyelopathic population. Spine 2001; 26(16):1760-1764

10 Ferguson RJL, Caplan LR. Cervical spondylitic myelopathy. Neurol Clin 1985;3(2):373-382

11 Firooznia H, Ahn JH, Rafii M, Ragnarsson KT. Sudden quadriplegia after a minor trauma. The role of preexisting spinal stenosis. Surg Neurol 1985;23(2):165-168

12 Lad SP, Patil CG, Berta S, Santarelli JG, Ho C, Boakye M. National trends in spinal fusion for cervical spondylotic myelopathy. Surg Neurol 2009;71(1):66-69

13 Wu JC, Ko CC, Yen YS, et al. Epidemiology of cervical spondylotic myelopathy and its risk of causing spinal cord injury: a national cohort study. Neurosurg Focus 2013;35(1):E10

14 Nouri A, Tetreault L, Singh A, Karadimas SK, Fehlings MG. Degenerative cervical myelopathy: epidemiology, genetics and pathogenesis. Spine 2015;40(12):E675-E693

15 Taitz C. Anatomical observations of the developmental and spondylotic cervical spinal canal in South African blacks and whites. Clin Anat 1996;9(6):395-400

16 Lee MJ, Cassinelli EH, Riew KD. Prevalence of cervical spine stenosis. Anatomic study in cadavers. J Bone Joint Surg Am 2007; 89(2):376-380 
17 Singh S, Kumar D, Kumar S. Risk factors in cervical spondylosis. J Clin Orthop Trauma 2014;5(4):221-226

18 Law MDJr, Bernhardt M, White AA, III. Cervical spondylotic myelopathy: a review of surgical indications and decision making. Yale J Biol Med 1993;66(3):165-177

19 Clark CR. Indications and surgical management of cervical myelopathy. Semin Spine Surg 1989;1(4):254-261

20 Kawakami M, Tamaki T, Iwasaki H, Yoshida M, Ando M, Yamada H. A comparative study of surgical approaches for cervical compressive myelopathy. Clin Orthop Relat Res 2000; (381):129-136

21 Hu Y, Lv G, Ren S, Johansen D. Mid- to long-term outcomes of cervical disc arthroplasty versus anterior cervical discectomy and fusion for treatment of symptomatic cervical disc disease: a systematic review and meta-analysis of eight prospective randomized controlled trials. PLoS One 2016;11(2):e0149312

22 Gupta A, Rajshekhar V. Functional and radiological outcome in patients undergoing three level corpectomy for multi-level cervical spondylotic myelopathy and ossified posterior longitudinal ligament. Neurol India 2016;64(1):90-96

23 LuoJ, Cao K, Huang S, et al. Comparison of anterior approach versus posterior approach for the treatment of multilevel cervical spondylotic myelopathy. Eur Spine J 2015;24(8):1621-1630

24 Klineberg E. Cervical spondylotic myelopathy: a review of the evidence. Orthop Clin North Am 2010;41(2):193-202

25 Zhu B, Xu Y, Liu X, Liu Z, Dang G. Anterior approach versus posterior approach for the treatment of multilevel cervical spondylotic myelopathy: a systemic review and meta-analysis. Eur Spine J 2013;22(7):1583-1593

26 Edwards CC II, Riew KD, Anderson PA, Hilibrand AS, Vaccaro AF. Cervical myelopathy. current diagnostic and treatment strategies. Spine J 2003;3(1):68-81

27 Lee CH, Lee J, Kang JD, et al. Laminoplasty versus laminectomy and fusion for multilevel cervical myelopathy: a meta-analysis of clinical and radiological outcomes. J Neurosurg Spine 2015; 22(6):589-595

28 van Geest S, de Vormer AM, Arts MP, Peul WC, VleggeertLankamp CL. Long-term follow-up of clinical and radiological outcome after cervical laminectomy. Eur Spine J 2015; 24(Suppl 2) :229-235

29 Yoshida M, Otani K, Shibasaki K, Ueda S. Expansive laminoplasty with reattachment of spinous process and extensor musculature for cervical myelopathy. Spine 1992;17(5):491-497

30 O'Brien MF, Peterson D, Casey AT, Crockard HA. A novel technique for laminoplasty augmentation of spinal canal area using titanium miniplate stabilization. A computerized morphometric analysis. Spine 1996;21(4):474-483

31 Hirabayashi K, Satomi K. Operative procedure and results of expansive open-door laminoplasty. Spine 1988;13(7):870-876

32 Macagno A, Liu S, Marascalchi BJ, et al. Perioperative risks associated with cervical spondylotic myelopathy based on surgical treatment strategies. Int J Spine Surg 2015;9:24 